\title{
Myocardial Dysfunction in Group B Streptococcal Shock
}

\author{
KEITH J. PEEVY, STEPHEN A. CHARTRAND, HOLLIS J. WISEMAN, ROBERT C. BOERTH, \\ AND RICHARD D. OLSON \\ Departments of Pediatrics and Pharmacology, University of South Alabama, College of Medicine, \\ Mobile, Alabama 36617
}

\begin{abstract}
A rabbit model of group B Streptococcal (GBS) shock was used to determine if myocardial dysfunction contributes to GBS shock and, if so, to ascertain if prostaglandins modulate this dysfunction. The infusion of heat-killed GBS (group I) produced a dramatic decrease in the first derivative of left ventricular pressure with respect to time $(\mathrm{LVdP} / \mathrm{dt})$ from baseline values $(p<0.05) . \mathrm{LVdP} /$ $\mathrm{dt}$ remained stable in rabbits pretreated with indomethacin (group II) and in saline-infused control rabbits (group III), and was significantly different at $30 \mathrm{~min}$ from $\mathrm{LVdP} / \mathrm{dt}$ in group I $(p<0.05)$. Values for group I mean arterial pressure, cardiac output, pulmonary vascular resistance, and heart rate and for $\mathrm{pH}$ and $\mathrm{pO}_{2}$ after GBS infusion were all significantly different from baseline values and from postinfusion values for groups II and III $(p<0.05)$. Systemic vascular resistance and left ventricular end diastolic pressure did not change significantly in any group at any time interval. These results indicate a primary role for myocardial dysfunction in the pathogenesis of GBS shock, and suggest strongly that prostaglandins modulate GBSinduced myocardial dysfunction. (Pediatr Res 19:511-513, 1985)
\end{abstract}

\section{Abbreviations}

GBS, group B Streptococcus

PG, prostaglandins

PAP, pulmonary artery pressure

$\mathrm{CO}$, cardiac output

HR, heart rate

$\mathrm{LVdP} / \mathrm{dt}$, the first derivative of left ventricular pressure with respect to time

PVR, pulmonary vascular resistance

IND, indomethacin

TB2, thromboxane B2

MAP, mean arterial pressure

Septic shock due to GBS is a significant cause of mortality in the human fetus and neonate $(1,2)$. Efforts to identify at-risk pregnancies and to prevent vertical transmission to the fetus are often unsuccessful (1). Conventional treatment of the septic neonate with antibiotics and pressor agents frequently fails to reverse the shock process (1). Improved survival in neonates affected by GBS shock depends on a clearer understanding of the pathogenesis of septic shock, and on the development of new therapeutic modalities aimed at interrupting the shock process.

Received August 6, 1984; accepted January 24, 1985.

Reprint requests Dr. Keith J. Peevy, Department of Pediatrics, University of South Alabama, 2451 Fillingim Street, Mobile, AL 36617.

This work was funded by a Grant from the Alabama Chapter, American Heart Association.
A variety of animal models for GBS sepsis has been developed for the study of therapeutic strategies and to assess the hemodynamic and hematologic alterations produced by GBS shock. Short et al. ${ }^{3}$ demonstrated an increased survival in the suckling rat model of GBS when animals were treated with prostaglandin synthetase inhibitors. In separate studies in piglets, Runkle et al. (4) and Lunyong and Smith (5) found that infusions of live GBS produced elevated TB2 levels and an increase in PAP. The changes in TB2 and PAP were inhibited by treatment with IND, further suggesting a role for PG in GBS shock. Rojas et al. (6) have isolated a toxic agent from GBS which in sheep produces elevated PAP, increased pulmonary vascular permeability, granulocytopenia, and increased levels of thromboxane and a prostacyclin metabolite (6-Keto-PGFl $\alpha$ ) in lung lymph. Pretreatment with IND prevented the increased PAP and prevented the rise in TB2 and 6-Keto-PGFl $\alpha$ levels in lung lymph. These data from different animal models support previous studies of endotoxin shock suggesting a major pathogenetic role for PG endoperoxides (7).

Although PG are strongly implicated in GBS shock, the possibility that PG may modulate shock through the production of myocardial dysfunction has not been investigated. The purposes of this study were to determine if myocardial dysfunction contributes to GBS shock, and, if so, to ascertain if PG modulate this dysfunction.

\section{MATERIALS AND METHODS}

Animal preparation. Adult New Zealand White rabbits received pentobarbital anesthesia and were placed on a small animal ventilator after tracheostomy. A midline sternotomy was performed, and catheters were inserted into the main pulmonary artery and left ventricle for measurement of PAP, LVdP/dt, and left ventricular end diastolic pressure. Femoral arterial and venous catheters were placed for measurement of MAP, HR, arterial blood gases, and administration of GBS and pharmacologic agents. A $5.0 \mathrm{~mm}$ Statham flow probed attached to a Zepada flow meter was placed on the ascending aorta for measurement of CO. Pulmonary vascular resistance (PVR) was calculated as mean PAP/CO and systemic vascular resistance was calculated as $\mathrm{MAP} / \mathrm{CO}$. All hemodynamic variables were recorded on a model R411 Beckman chart recorder. After surgery, animals were stabilized for $30 \mathrm{~min}$. Arterial blood gases were measured every $15 \mathrm{~min}$ and ventilation adjusted to maintain an alkalotic, hyperventilated state $(\mathrm{pH} \geq 7.6)$ so that anticipated GBS-induced alterations in $\mathrm{pH}$ would have minimal impact on MAP, $\mathrm{CO}$, and $\mathrm{LVdP} / \mathrm{dt}$.

$G B S$ preparation. A strain of GBS isolated from the blood of an infant dying with shock was used in all experiments. Before each series of experiments the organism was injected into mice, and isolated colonies from a heart blood subculture were grown overnight on blood agar. Bacteria were suspended in sterile, nonpyrogenic saline to a quantified density of $10^{11}$ colony- 
forming units per milliliter and then killed by heating to $100^{\circ} \mathrm{C}$ for $15 \mathrm{~min}$.

Experimental sequence. Animals were assigned randomly to one of three experimental groups. Animals in group I $(n=10)$ were given heat-killed GBS by constant infusion $(0.3$ to 0.5 $\mathrm{ml} / \mathrm{kg} / \mathrm{min}$ of $10^{11} \mathrm{GBS} / \mathrm{ml}$ ) to a total dose of $10^{12}$ organisms per kilogram. Values for the measured and derived hemodynamic variables and for arterial blood gases were obtained at baseline and $30 \mathrm{~min}$ after the beginning of the infusion. Three animals in group I were given IND $(4 \mathrm{mg} / \mathrm{kg})$ after 30 -min variables were determined. Animals in group II $(n=6)$ were pretreated with IND $(4 \mathrm{mg} / \mathrm{kg}) 30 \mathrm{~min}$ before an infusion of heat-killed GBS was given in the same manner as in group I. Hemodynamic and blood gas values were determined at baseline, after IND, and at 30 and 60 min after the beginning of the GBS infusion. Control animals (group III) $(n=6)$ received a volume of sterile saline equal to the volume of heat-killed GBS used in groups I and II and had each variable assessed at the same times.

Statistical analysis was performed on each variable between groups at baseline and 30 min using one-way analysis of variance, and within groups at baseline and $30 \mathrm{~min}$ using the complete block design analysis of variance with Duncan's test. Survival to 120 min was compared for untreated animals in group I $(n=7)$, all IND-treated animals in group I $(n=3)$ and II $(n=6)$, and control animals $(n=6)$ using $\chi^{2}$ analysis. A $p$ value of $<0.05$ was considered significant for all comparisons.

\section{RESULTS}

Table 1 shows the values for $\mathrm{LVdP} / \mathrm{dt}$ and the other hemodynamic variables at baseline and $30 \mathrm{~min}$ in control animals (group III) and in the animals infused with GBS in the presence (group II) or absence (group I) of IND. The greater than $50 \%$ fall in $\mathrm{LVdP} / \mathrm{dt}$ seen in group $\mathrm{I}(p<0.05)$ was prevented by pretreatment with IND in group II. The $\mathrm{LVdP} / \mathrm{dt}$ in group II animals were comparable to that in the control group.

The hemodynamic variables obtained from the three study groups are shown in Table 1. Group I values for MAP, CO, PVR, and HR at 30 min were significantly different from the values at $30 \mathrm{~min}$ in groups II and III. There were no significant differences within or between groups II and III at any time interval.

Table 2 lists values for $\mathrm{pH}$ and $\mathrm{pO}_{2}$ at baseline and $30 \mathrm{~min}$ for each group and at $60 \mathrm{~min}$ for groups II and III. The $\mathrm{pH}$ and $\mathrm{pO}_{2}$ fell significantly in group I by $30 \mathrm{~min}$. A small but statistically significant drop in $\mathrm{pH}$ from baseline was noted in group II at 60 min but the value was not significantly different from that in group III.

Survival was monitored for a minimum of $120 \mathrm{~min}$ in all groups. The six control animals survived to $120 \mathrm{~min}$. Seven animals in group I received only GBS. Four animals survived to $60 \mathrm{~min}$ and two to $120 \mathrm{~min}$. Three animals in group I received IND after the 30-min assessment of variables. All three of those animals and all of the animals pretreated with IND (six of six) in group II survived to $120 \mathrm{~min}$. Survival at $120 \mathrm{~min}$ was compared using $\chi^{2}$ analysis of GBS-infused rabbits with and without IND treatment. IND-treated animals had significantly greater survival $\left(\chi^{2}=6.32, p<0.05\right)$.

\section{DISCUSSION}

Our study demonstrates myocardial dysfunction in an adult rabbit model of septic shock induced by GBS. Deterioration of $\mathrm{LVdP} / \mathrm{dt}$ in response to heat-killed GBS infusion was rapid and was associated with significant declines in MAP, $\mathrm{CO}, \mathrm{HR}, \mathrm{pH}$, and $\mathrm{pO}_{2}$, and a rise in PVR. The hemodynamic changes produced by GBS (group I) were prevented by the prostaglandin synthetase inhibitor IND (group II). This suggests that alteration of myocardial function in GBS shock is PG dependent.

The magnitude of $\mathrm{LVdP} / \mathrm{dt}$ is affected by HR, SVR, preload, and the intrinsic contractile state of the heart $(8,9)$. The $20 \%$ fall in HR induced by GBS in group I could be partly responsible for the observed decline in $\mathrm{LVdP} / \mathrm{dt}$. However, the relatively

Table 2. Values for $\mathrm{pH}$ and $\mathrm{pO}_{2}$ measured at baseline and at 30-min intervals after the initiation of GBS infusion (groups I and II) or saline infusion (group III) (mean $\pm S E$ )

\begin{tabular}{cll}
\hline & \multicolumn{1}{c}{$\mathrm{pH}$} & $\mathrm{pO}_{2}$ (torr) \\
\hline Group I & & \\
Baseline & $7.62 \pm 0.03$ & $88 \pm 5$ \\
30 min & $7.41 \pm 0.05^{*}$ & $53 \pm 6^{*}$ \\
Group II & & \\
Baseline & $7.65 \pm 0.07$ & $79 \pm 9$ \\
IND & $7.67 \pm 0.06$ & $90 \pm 7$ \\
$30 \mathrm{~min}$ & $7.61 \pm 0.05 \dagger$ & $85 \pm 5 \dagger$ \\
$60 \mathrm{~min}$ & $7.56 \pm 0.05^{*}$ & $92 \pm 6$ \\
Group III & & \\
Baseline & $7.60 \pm 0.03$ & $73 \pm 12$ \\
$30 \mathrm{~min}$ & $7.55 \pm 0.03$ & $70 \pm 10$ \\
$60 \mathrm{~min}$ & $7.59 \pm 0.05$ & $84 \pm 9$
\end{tabular}

* Value significantly different from baseline $(p<0.05)$.

$\dagger$ Values significantly different than 30 -min value in group I $(p<$ $0.05)$.

Table 1. Hemodynamic variables assessed at baseline and at 30-min intervals after the initiation of GBS infusion (groups I and II) or saline infusion (group III) (mean \pm SE)

\begin{tabular}{|c|c|c|c|c|c|c|c|}
\hline & $\begin{array}{c}\mathrm{LVdP} / \mathrm{dt} \\
(\mathrm{mm} \mathrm{Hg} / \mathrm{s})\end{array}$ & $\begin{array}{c}\text { MAP } \\
(\mathrm{mm} \mathrm{Hg})\end{array}$ & $\begin{array}{c}\mathrm{CO} \\
(\mathrm{L} / \mathrm{min})\end{array}$ & $\begin{array}{c}\text { PVR } \\
(\mathrm{mm} \mathrm{Hg} / \mathrm{L} / \mathrm{min})\end{array}$ & $\begin{array}{c}\text { Systemic } \\
\text { vascular } \\
\text { resistance } \\
(\mathrm{mm} \mathrm{Hg} / \mathrm{L} / \mathrm{min})\end{array}$ & $\begin{array}{c}\text { Left ventricular } \\
\text { end diastolic } \\
\text { pressure } \\
(\mathrm{mm} \mathrm{Hg})\end{array}$ & $\begin{array}{c}\text { HR } \\
\text { (beats/min) }\end{array}$ \\
\hline \multicolumn{8}{|c|}{ Group I $(n=10)$} \\
\hline Baseline & $4838 \pm 250$ & $77 \pm 3$ & $0.190 \pm 0.014$ & $8.3 \pm 0.9$ & $42.5 \pm 3.7$ & $0.6 \pm 0.3$ & $253 \pm 9$ \\
\hline $30 \mathrm{~min}$ & $2358 \pm 555^{*}$ & $47 \pm 7^{*}$ & $0.101 \pm 0.022^{*}$ & $23.4 \pm 8.0^{*}$ & $48.1 \pm 10.0$ & $1.9 \pm 0.6$ & $216 \pm 9^{*}$ \\
\hline \multicolumn{8}{|c|}{ Group II $(n=6)$} \\
\hline Baseline & $4858 \pm 333$ & $78 \pm 5$ & $0.195 \pm 0.020$ & $7.2 \pm 0.8$ & $42.3 \pm 5.6$ & $2.2 \pm 0.9$ & $251 \pm 3$ \\
\hline IND & $4678 \pm 458$ & $75 \pm 6$ & $0.183 \pm 0.022$ & $7.9 \pm 1.0$ & $44.9 \pm 6.9$ & $1.8 \pm 0.9$ & $255 \pm 7$ \\
\hline $30 \mathrm{~min}$ & $4981 \pm 399 \dagger$ & $82 \pm 4 \dagger$ & $0.211 \pm 0.031 \dagger$ & $9.5 \pm 2.0 \dagger$ & $43.9 \pm 7.8$ & $3.2 \pm 1.1$ & $246 \pm 8 \dagger$ \\
\hline $60 \mathrm{~min}$ & $4770 \pm 371$ & $85 \pm 8$ & $0.201 \pm 0.034$ & $11.1 \pm 3.0$ & $41.2 \pm 7.2$ & $3.8 \pm 0.9$ & $231 \pm 6$ \\
\hline \multicolumn{8}{|c|}{ Group III $(n=6)$} \\
\hline Baseline & $5208 \pm 581$ & $79 \pm 8$ & $0.219 \pm 0.017$ & $8.5 \pm 0.8$ & $36.3 \pm 0.2$ & $1.3 \pm 0.9$ & $244 \pm 8$ \\
\hline $30 \mathrm{~min}$ & $5417 \pm 480 \dagger$ & $81 \pm 7 \dagger$ & $0.212 \pm 0.014 \dagger$ & $8.5 \pm 1.2 \dagger$ & $38.5 \pm 2.3$ & $2.2 \pm 1.0$ & $246 \pm 9 \dagger$ \\
\hline $60 \mathrm{~min}$ & $4970 \pm 335$ & $76 \pm 5$ & $0.189 \pm 0.020$ & $8.5 \pm 1.3$ & $41.0 \pm 2.0$ & $2.3 \pm 0.9$ & $242 \pm 7$ \\
\hline
\end{tabular}

* Significantly different from baseline $(p<0.05)$.

$\dagger$ Significantly different than 30 -min value in group I $(p<0.05)$. 
small change in HR would not totally explain the rapid $50 \%$ fall in $\mathrm{LVdP} / \mathrm{dt}$ as shown in Table 1 . Since systemic vascular resistance and left ventricular end diastolic pressure (index of preload) did not change significantly in any group, the observed fall in $\mathrm{LVdP} / \mathrm{dt}$ induced by GBS could not be related to changes in these variables.

Alterations in $\mathrm{pH}$ may have a significant impact on myocardial contractility $(8,10)$. We attempted to minimize these affects by hyperventilatory alkalosis prior to GBS infusion. Although a significant fall in $\mathrm{pH}$ occurred by $30 \mathrm{~min}$ in group $\mathrm{I}$, the absolute value was still within the acceptable physiological range (7.41) Thus, it is unlikely that the change in $\mathrm{pH}$ associated with GBS infusion produced the dramatic fall of $\mathrm{LVdP} / \mathrm{dt}$. Furthermore, a significant fall in $\mathrm{pH}$ occurs $1 \mathrm{~h}$ after GBS infusion in group II animals; this was not associated with any significant change in $\mathrm{LVdP} / \mathrm{dt}$

Profound hypoxemia may also cause myocardial dysfunction (10). While the 30 -min value for $\mathrm{pO}_{2}$ in group I fell significantly from baseline, the absolute value was greater than $50 \mathrm{~mm} \mathrm{Hg}$ and was not statistically different from the 30 -min value in control animals. Thus, while reduction of $\mathrm{HR}, \mathrm{pH}$, and $\mathrm{pO}_{2}$ may have plaved a small role in producing the myocardial dysfunction seen in this model, they do not adequately explain the magnitude of the fall in $\mathrm{LVdP} / \mathrm{dt}$ induced by GBS.

The protective effect of IND observed in group II suggests that PG may in some way modulate the myocardial dysfunction produced by GBS. Theoretical possibilities for $P G$ involvement in septic myocardial dysfunction include: 1) a PG-mediated increase in coronary vascular resistance resulting in diminished or altered distribution of coronary perfusion $(11,12) ; 2)$ a PGmediated change in PVR producing excessive right ventricular afterload with right ventricular dilatation, septal dysfunction, and mechanical interference with left ventricular function (13); 3 ) a direct effect of $P G$ on myocardial contractile function due to modulation of calcium channels or ion exchange mechanisms (14.15)

Survival of animals in this study was prolonged when IND was given either before or after GBS-induced shock. While the primary purposes of our study were to evaluate the effects of GBS and PG synthetase inhibition on myocardial function, the prolonged survival demonstrated in response to IND is interesting and confirms earlicr small animal studies of GBS and PG synthetase inhibition (3-5).
In summary, we have shown that myocardial dysfunction occurs in a rabbit model of GBS shock. PG synthetase inhibition by IND prevented GBS-induced myocardial dysfunction and significantly prolonged the survival of animals receiving GBS. These data suggest primary cardiac involvement in the evolution of GBS shock. Further studies are needed to delineate the mechanism(s) which produce myocardial dysfunction in GBS sepsis.

\section{REFERENCES}

1. Baker C 1977 From the National Institutes of Health: summary of the workshop on perinatal infections due to group B Streptococcus. J Infect Dis $136: 137-152$

2. Berqvist G, Holmberg G, Rydner T, Vaclavinkova V 1973 Intrauterine death due to infection with group B Streptococci. Acta Obstet Gynecol Scand 57:127-128

3. Short B, Miller M. Fletcher F 1982 Improved survival in the suckling rat model of group B Streptococcal sepsis after treatment with nonsteroidal antiinflammatory drugs. Pediatrics 70:343-347

4. Runkle B, Goldberg R, Clark M, Streitfield M, Setzer S, Buron E, Bancalari E 1983 Prostaglandins and hemodynamic events in group B beta strep (GBS) sepsis in indomethacin trated piglets. Pediatr Res 17:333A(1479)

5. Lunyong V Smith S 1983 Thromboxane and pulmonary hypertension following group $B$ beta strep infusion in newborn piglets: inhibiting effect of indomethacin. Pediatr Res 17:382A(1771)

6. Rojas J, Larsson L, Ogletree M, Brigham K, Stahlman M 1983 Effect of Cyclooxygenase inhibition on the response to group $\mathrm{B}$ streptococcal toxin in sheep. Pediatr Res 17:107-110

7. Hess ML, Hastillo A, Greenfield L 1981 Spectrum of cardiovascular function during gram-negative sepsis. Prog Cardiovasc Dis 23:279-298

8. Neill W 1976 Regulation of cardiac output. In: Levine HJ (ed) Clinical Cardiovascular Physiology. Grune and Stratton, New York, pp 121-142

9. Skelton C. Sonnenblick E 1976 Physiology of cardiac muscle. In: Levin HJ (ed) Clinical Cardiovascular Physiology. Grune and Stratton, New York, pp $57-120$

10. Brachfield N 1976 Diagnostic and therapeutic implications of inadequate myocardial oxygenation. In: Levine HJ (ed) Clinical Cardivascular Physiology Grune and Stratton, New York, pp 883-915

11. Gerritsen M, Cheli C 1983 Arachadonic acid and prostaglandin endoperoxide metabolism in isolated rabbit and coronary microvessels and isolated and cultivated coronary microvessel endothelial cells. $\mathrm{J}$ Clin Invest 72:16581671

12. Posner P, Lambert C 1982 Study of Prostaglandin $E_{1}$ and $F_{2} \alpha$ on isolated mammalian cardiac tissue. Pharmacology 25:26-32

13. Ghignone M, Girling L, Prewitt R 1984 Effect of increased pulmonary vascular resistance on right ventricular systolic performance in dogs. Am J Physio 246:H339-H343

14. Fozzard H 1977 Heart: excitation-contraction coupling. Ann Rev Physiol 39:201-220

15. Kecskemeti V, Keleman K, Knoll J 1976 Dose-dependent effect of prostaglandins on cardiac transmembrane potential. Acta Biol Med Germ 35:11731174 